\title{
Should doctors be able to exclude patients from pay-for-performance schemes?
}

\section{Martin Roland}

\section{Correspondence to}

Professor Martin Roland,

Department of Public Health and

Primary Care, Institute of Public

Health, University of Cambridge,

Cambridge, UK;

mr108@cam.ac.uk

Accepted 26 November 2015

Published Online First

30 December 2015

\section{SLinked}

http://dx.doi.org/10.1136/ bmjqs-2015-004602

\section{CrossMark}

To cite: Roland M. BMJ Qual Saf 2016;25:653-656.
In 2004, the UK introduced what was at the time the world's most ambitious pay-for-performance scheme, the Quality and Outcomes Framework or 'QOF'. Twenty five per cent of general practitioners' (GPs') pay was tied to a complex set of 136 quality indicators, the majority of which were extracted electronically from GPs' medical records. ${ }^{1}$ Typical indicators related to blood pressure control in hypertension or blood sugar control in patients with diabetes. However, GPs were given the opportunity to exclude patients from these quality calculations, and this was called exception reporting. If a GP 'exception reported' a patient (or an individual indicator), that patient (or indicator) was removed from the quality calculation with no financial penalty to the GP.

The rationale for exception reporting was that even the best evidence-based guidelines were never intended to apply to all patients who visit their doctor. For example, it would be inappropriate to expect a GP to try rigorously to control cholesterol in a patient with diabetes dying of lung cancer. Exception reporting was therefore designed to allow doctors' discretion to use their clinical judgement in deciding what treatments were appropriate for individual patients. The system was also designed so that doctors were not penalised if patients were noncompliant with requests for routine follow-up appointments or if patients did not wish to receive a particular investigation or treatment. The full list of reasons that doctors could record when deciding to exception report a patient is shown in box $1 .^{2}$

The most common reasons for exception reporting are logistical, that is, where the patient is recently registered or diagnosed, or where a specified service is not available. Together these account for
$40.6 \%$ of exception reports, though fewer than $0.01 \%$ are because the service is not available. Exceptions where the patient declined the intervention ('informed dissent') account for $30.1 \%$ of exception reports, with $26.3 \%$ of exception reports made on the basis of clinical judgement by the $\mathrm{GP}^{3}$

Although it helped to gain clinical support for the new pay-for-performance scheme, exception reporting has always been controversial. Government reports express concern that GP may manipulate exception reporting in order to maximise income at the expense of patient care ('gaming'). ${ }^{4}$ Others were concerned that patients who were exception reported might be those in particular need (eg, in socio-economically deprived areas) or those who were most difficult to treat. From a public health perspective, exception reporting might therefore lead to an increase in health inequality. How much have these fears been realised? Has exception reporting proved to be a 'charter for cheats', and have patients excluded from the scheme been deprived of healthcare from which they could benefit?

The overall rate of exception reporting has been relatively low, with an initial median rate of $5.3 \%$, which fell to $4.5 \%$ in $2008 / 2009$. However, $1 \%$ of practices initially excluded more than $15 \%$ of their patients. In 2008/2009, there was substantial variation in exception reporting between indicators, which ranged from $0 \%$ for seven indicators to $24 \%$ for beta blockade therapy for patients with coronary heart disease. In general, rates of exception reporting were lower for aspects of care that simply required measurement (median 2.7\%) than those that required an intermediate outcome to be achieved (median 5.7\%) and those that required a treatment to be given (median 


\section{Box 1 Eligible reasons for exception reporting}

Patients who have been recorded as refusing to attend review who have been invited on at least three occasions during the financial year to which the achievement payments relate.

- Patients for whom it is not appropriate to review the chronic disease parameters due to particular circumstances, for example, a patient who has a terminal illness or is extremely frail.

- Patients newly diagnosed or who have recently registered with the contractor who should have measurements made within 3 months and delivery of clinical standards within 9 months, for example, blood pressure or cholesterol measurements within target levels.

- Patients who are on maximum tolerated doses of medication whose levels remain sub optimal.

- Patients for whom prescribing a medication is not clinically appropriate, for example, those who have an allergy, contra indication or have experienced an adverse reaction.

- Where a patient has not tolerated medication.

- Where a patient does not agree to investigation or treatment (informed dissent) and this has been recorded in their patient record following a discussion with the patient.

- Where the patient has a supervening condition that makes treatment of their condition inappropriate, for example, cholesterol reduction where the patient has liver disease.

- Where an investigative service or secondary care service is unavailable.

10\%). ${ }^{3} 5$ The most recent figures show that the mean exception reporting rate for practices in England is $5.5 \% .^{6}$

Currently the 'gap' between actual performance and $100 \%$ achievement of quality targets is about equally divided between the targets being set below 100\% and patients being exception reported. ${ }^{7}$ However, when GPs were offered additional incentives for meeting higher targets in a local scheme to improve cardiovascular disease care, the higher targets were achieved largely as a result of increased exception reporting. ${ }^{8}$ The upper thresholds beyond which additional payments are made have also been increased from time to time, and this may lead also to an increase in exception reporting. For example, Kontopantelis et $a l^{9}$ analysed the impact of increases in the influenza immunisation target and found that introduction of a new higher target was associated with an overall $0.26 \%$ increase in the rate of exception reporting for the indicator, but the increase in exception reporting was $0.5 \%$ for practices that started the year further from the target. This is consistent with reports from GPs that they use exception reporting at the end of the payment year to help them meet unmet targets. ${ }^{10}$

Although patients living in socio-economically deprived areas are more likely to be exception reported, ${ }^{11}{ }^{12}$ these effects are generally small, with age, gender and socio-economic position explaining only $2.7 \%$ of the overall variance in national rates of exception reporting. ${ }^{5}$ However, rates of exception reporting are much higher among patients in residential and nursing homes, an important group of patients, often with complex multimorbidities. ${ }^{13}$ Dalton et $a l^{14}$ in a small study in London found that exception reporting rates for diabetes were also substantially higher among disadvantaged groups, including ethnic minorities and those living in deprived areas. It is certainly the case that GPs and practice staff regard exception reporting as an important safeguard against inappropriate treatment of individual patients, ${ }^{10}$ and indeed, one author has argued that doctors practising effective shared decision-making should have higher rates of exception reporting, that is, that exception reporting is a marker of quality. ${ }^{15}$ Although this may be a somewhat extreme view, exception reporting avoids the risk that pay-for-performance schemes result, as has been reported to occur in the USA, in doctors actively disenrolling non-compliant patients. ${ }^{16}$

In this edition of the journal, Kontopantelis et $a l^{17}$ examine the relation between exception reporting at individual patient level and mortality over the subsequent year. Older patients with multimorbidity were more likely to be exception reported and patients were more likely to die in the year following being exempted from the P4P scheme both when the GP recorded a clinical contraindication (hazard ratio 1.37) and when the patient was recorded as declining the procedure or treatment (hazard ratio 1.2). Possible explanations include GPs appropriately excluding patients or patients appropriately declining treatments near the end of life, or-alternatively-patients inappropriately not being offered or accepting evidence-based care and hence dying prematurely. The analyses in this paper exclude 'logistical' reasons for exception reporting (the patient recently registered or diagnosed or a specified service not being available)probably a reasonable approach in paper that focuses on GPs' clinical judgement and patients' wishes in relation to interventions that form part of the QOF. The number of conditions the patient had was a strong predictor of exception reporting for both clinical reasons and informed dissent, for example, the ORs for the GP exception reporting on clinical grounds were 4.3, 16.3 and 68.7 with two, three and four or more conditions, compared with patients with one condition. This strong association of exception reporting with multimorbidity relates to another current clinical discussion, namely the concern that 
'evidence-based guidelines', which have largely been developed on patients with single conditions, might be inappropriate when applied to patients with multimorbidity ${ }^{18}$ and it may be that GPs are more likely to judge that indicators in the QOF are inappropriate for their patients who have multiple comorbidities. Kontopantelis et al also examined the phenomenon of 'met' exception reporting, that is, patients who were excluded but in whom subsequent analysis of the data showed that the quality indicator had in fact been met. For example, for patients excepted from the diabetes hypertension indicator, more than half of patients had actually achieved the required blood pressure control by the end of the recording year.

The finding that exception reporting is associated with increased risk of death is therefore an important one, but it does not answer the question of whether the decisions by doctors (exception reporting on clinical grounds) or by patients (informed dissent) are detrimental to patients' health. Overall, rates of exception reporting are relatively low and, although there is some evidence of gaming, this does not appear from current evidence to be on a large scale. Practices with persistently high levels of exception should receive a higher degree of external scrutiny, and we need to know more about those individual indicators where large numbers of patients are excluded. However, we still do not know whether the ability of doctors to exclude patients from the P4P scheme has been in the interests of patients or not. Exception reporting continues to have high face validity among doctors who believe that it reduces the risk of inappropriate treatment, but it is rarely used in pay-for-performance schemes in other countries.

The question of whether GPs should be able to exercise their clinical judgement in deciding that a particular quality indicator is not appropriate to apply to the patient in front of them plays into a wider debate about the place of clinical judgement in medical care. For example, the BMJ's 'Too Much Medicine' campaign and the ABIM's 'Choosing Wisely' campaigns ${ }^{19}{ }^{20}$ argue that overdiagnosis, overinvestigation and overtreatment pose a positive threat to patients' health. In the case of the QOF, the payer (the National Health Service) has chosen to trust the judgement of doctors in excluding patients from the scheme, with only light-touch external inspection.

More contentious and still unresolved is whether doctors' clinical judgement should be similarly respected when deciding to apply or ignore a clinical guideline for an individual patient, whether or not it forms part of a P4P scheme. We have previously argued that, given the uncertainties about how single condition guidelines should be applied to patients with multimorbidity, greater scope should be given to doctors to apply their own clinical judgement to patients. ${ }^{21}$ The experience of exception reporting suggests that doctors make clinical decisions to over-ride guidelines relatively uncommonly, but more work is needed to understand the guidelines that are often ignored (are they poor guidelines or just difficult to implement?), and whether and when harms result to patients when doctors use their clinical judgement to over-ride guidelines. The criteria set out for excluding patients also emphasise that decisions about investigations and treatments should be shared between doctors and patients, with both parties having a legitimate say in what is appropriate for each individual patient.

Competing interests MR was one of the clinical advisers who contributed between 2001 and 2003 to pay negotiations between the British Medical Association and the National Health Service. These negotiations resulted in the Quality and Outcomes Framework which formed part of the 2004 GP contract and included development of the concept of exception reporting.

Provenance and peer review Commissioned; internally peer reviewed.

\section{REFERENCES}

1 Roland M. Linking physicians' pay to quality of care-a major experiment in the United Kingdom. N Engl J Med 2004;351:1448-54.

2 BMA (British Medical Association), NHS England, NHS Employers. 2014/15 General Medical Services (GMS) Contract Quality and Outcomes Framework (QOF). Guidance for GMS contract 2014/15. http://www.nhsemployers.org/ /media/ Employers/Documents/Primary\%20care\%20contracts/QOF/ 2014-15/2014-15\%20General\%20Medical\%20Services\% 20contract $\% 20-\% 20 \% 20$ Quality $\% 20$ and $\% 20$ Outcomes $\%$ 20Framework\%20Guidance.pdf

3 Doran T, Kontopantelis E, Fullwood C, et al. Exempting dissenting patients from pay for performance schemes: retrospective analysis of exception reporting in the UK Quality and Outcomes Framework. BMJ 2012;344:e2405.

4 Audit Commission. Paying GPs to improve quality. Auditing payments under the Quality and Outcomes Framework. Audit Commission 2011. http://webarchive.nationalarchives.gov.uk/ 20150421134146/http://archive.audit-commission.gov.uk/ auditcommission/subwebs/publications/studies/studyPDF/ 100261.pdf

5 Doran T, Fullwood C, Reeves D, et al. Exclusion of patients from pay-for-performance targets by English physicians. N Engl J Med 2008;359:274-84.

6 Health and Social Care Information Centre. Quality and Outcomes Framework (QOF)-2014-15. October 2015. http:// www.hscic.gov.uk/catalogue/PUB18887

7 Fleetcroft R, Steel N, Cookson R, et al. "Mind the gap!" Evaluation of the performance gap attributable to exception reporting and target thresholds in the new GMS contract: national database analysis. BMC Health Serv Res 2008;8:131.

8 Pape U, Huckvale K, Car J, et al. Impact of 'stretch' targets for cardiovascular disease management within a local pay-for-performance programme. PLOS ONE 2015;10: e0119185.

9 Kontopantelis E, Doran T, Gravelle H, et al. Family doctor responses to changes in incentives for influenza immunization under the UK Quality and Outcomes Framework pay-for-performance scheme. Health Serv Res 2012;47:1117-36. 


\section{Editorial}

10 Campbell S, Hannon K, Lester H. Exception reporting in the Quality and Outcomes Framework. Br J Gen Pract 2011;61: e183-9.

11 Sigfrid L, Turner C, Crook D, et al. Using the UK primary care Quality and Outcomes Framework to audit health care equity: preliminary data on diabetes management. J Public Health (Oxf) 2006;28:221-5.

12 Simpson C, Hannaford P, McGovern M, et al. Are different groups of patients with stroke more likely to be exclude from the new UK general medical services contract? A cross-sectional retrospective analysis of a large primary care population. BMC Fam Pract 2007;8:56.

13 Shah S, Carey I, Harris T, et al. Quality of chronic disease care for older people in care homes and the community in a primary care pay for performance system: retrospective study. BMJ 2011;342:d912.

14 Dalton A, Alshamsan R, Majeed A, et al. Exclusion of patients from quality measurement of diabetes care in the UK payfor-performance programme. Diabet Med 2011;28:525-31.
15 Hopayian K. Exception reporting as a quality marker. Br J Gen Pract 2013;63:315.

16 McDonald R, Roland M. Pay for performance in primary care in England and California: comparison of unintended consequences. Ann Fam Med 2009;7:121-7.

17 Kontopantelis E, Springate D, Ashcroft D, et al. Associations between exception reporting and survival outcomes in the UK's primary care pay-for-performance scheme: a retrospective cohort study. BMJ Qual Saf 2016;25:657-70.

18 Hughes L, McMurdo M, Guthrie B. Guidelines for people not for diseases: the challenges of applying UK clinical guidelines to people with multimorbidity. Age Ageing 2013;42:62-9.

19 ABIM Foundation. Choosing Wisely. 2015. http://www. choosingwisely.org/

20 British Medical Journal Too Much Medicine. 2015. http:// www.bmj.com/too-much-medicine

21 Roland M, Paddison C. Better management of patients with multimorbidity. BMJ 2013;346:f2510. 